\title{
Editorial
}

\section{Everyday Technology for Independence and Care}

This issue of Technology and Disability is a special issue containing elaborations of the best papers presented at the AAATE conference 2011.

Last year the $11^{\text {th }}$ AAATE conference was held in Maastricht in the Netherlands. The conference covered a wide range of topics within the domains of Assistive technology, Care technology and Accessibility. We had the pleasure of hosting 9 keynote addresses, 155 oral presentations, 24 poster presentations and an interesting exhibition. The high quality keynote speeches were given by Jan Engelen and Christian Bühler, Two Decennia of Advancement of Assistive Technology in Europe. They addressed part of the content of the material also available in Technology and Disability Vol. 23; issue 3. Paul Timmers, European Assistive Technology in Perspective. Josée Hansen, Everyday Technology for Independence and Care: Need, Benefit, Cost. André Knottnerus, Increasing Needs, Increasing Challenges. Luc de Witte, Challenges and $\mathrm{Op}$ portunities for Europe (and the AAATE); Inmaculada Placencia Porrero, Everyday Technology for Independence and Care: Research and Policy Evolution; Jerry Weisman, Assistive Technology Quality Assurance and the RESNA Certification Program; Alan Newell and MM Training presented their refreshing Accessible and Personalised Self-Service Terminals; and the conference was closed by Thijs Soede with his lecture titled AAATE, A Society of Men and Women with Passion and Compassion. The proceedings of this memorable conference have been published with IOS press as Volume 29 in their Assistive Technology Research series.

Thanks to the hard work of the reviewers for the conference, most of whom are also on the review board of this journal, the organisation of the conference has been able to select 10 papers that were nominated for the best paper award prior to the conference. During the conference these 10 papers were additionally eval- uated by the programme committee on the basis of its presentation by one of the authors. This resulted in Claude Vincent being presented, at the closure of the conference, the best Paper award of AAATE 2011.

As the basis for this special issue the 10 nominated conference papers were considered. However, a conference paper is not the same as a journal article, some of the nominated papers presented preliminary results at the conference and could not yet be elaborated into journal contributions and some authors were not found willing to convert their paper into an article.

Therefore, you will find six articles in this issue out of the original ten nominated papers. We are proud to have the award-winning Bergeron, Vincent and Boucher article among these six. They present an excellent study on the experiences of parents in wheelchairs.

A further three of these papers deal with application of assistive robotics but from very different perspectives; a paper by Nakamura et al. on an evaluation method, a paper on system development by Inoue et al. and a final paper on needs assessment in relation to robot development by Pigini et al. Then there is a paper by van der Heide et.al. on a tele-care application and a paper by Brandt and Iwarsson on the development of an instrument for participation assessment.

Also in this issue you find an excellent review by Tuula Hurnasti of the book Assistive Technologies and Other Supports for People With Brain Impairment by Marcia Scherer.

The AAATE conference is a biannual event and besides this journal one of the main information exchange occasions for members of our association. We are already looking forward to the 2013 edition of this conference in Vilamoura, Portugal on 19-22 September 2013. Make sure to submit your excellent material in time to make this conference as rich as the conference in Maastricht.

Gert Jan Gelderblom Editor in Chief 